\title{
HIPERNEFROMA EN RIÑÓN NATIVO DE PACIENTE CON TRASPLANTE RENAL
}

\author{
J. HERRERA PUERTO*, F. CARAVACA**, J.L. CASTAÑO CASASECA*, \\ J. SOLER FERNÁNDEZ*, S. ASUAR AYDILLO*
}

*Servicio de Urología. **Servicio de Nefrología. Hospital Regional Infanta Cristina. Badajoz.

Actas Urol Esp. 27 (5): 391-393, 2003

\section{RESUMEN}

"HIPERNEFROMA EN RIÑÓN NATIVO DE PACIENTE CON TRASPLANTE RENAL"

Los pacientes urémicos, particularmente en programas de diálisis, pueden presentar sobre sus riñones quistes bilaterales con una frecuencia significativa. Esta entidad definida como patología renal quística adquirida se encuentra asociada en su evolución con la aparición de patología maligna renal.

Se trata de un enfermo sometido a diálisis antigua y trasplantado renal que ulteriormente desarrolló una neoplasia renal asintomática.

Se analizan los aspectos epidemiológicos, clínico-diagnósticos así como terapéuticos de la asociación de quistes renales adquiridos y cáncer renal.

PALABRAS CLAVE: Hipernefroma. Diálisis. Quistes Renales.

\section{ABSTRACT}

"HYPERNEPHROMA IN NATIVE KIDNEY OF PATIENT WITH RENAL TRANSPLANT"

The uremic patients, specially in periodic dialysis, may present bilateral kidneys cysts with high frequency. This pathology, known as acquired cyst renal disease, is found associated in its evolution with the emergence renal malignant disease.

A patient who undergoing chronic dialysis and renal transplant subsequently developed an asymptomatic renal neoplasm.

The epidemiological, clinical, diagnostic aspects and therapeutic of the acquired cysts renal and your association with renal cancer are analyzed.

KEY WORDS: Hypernephroma. Dialysis. Renal Cysts.

$L^{2}$ os pacientes en hemodiálisis crónica pueden presentar quistes renales múltiples bilaterales en una proporción elevada ${ }^{1}$, conociéndose como enfermedad renal quística adquirida (E.R.Q.A), y además desarrollar lesiones benignas y malignas en sus riñones naturales ${ }^{2}$.

El criterio más aceptado es el antecedente de haber recibido diálisis, al menos durante 3 años, pero esta enfermedad puede aparecer en insuficientes renales que nunca se dializaron y en aquellos con diálisis peritoneal ${ }^{1}$.
Se comunica un nuevo caso a la literatura y se hace una puesta a punto bibliográfica a cerca de la presentación de cáncer renal en pacientes urémicos.

\section{CASO CLÍNICO}

Varón de 55 años con antecedentes de hemodiálisis durante 5 años por nefropatía hipertensiva maligna y trasplante renal 3 años después, remitido desde la consulta de nefrología para valoración de lesión compleja en riñones quísticos conocidos desde hacía varios años. 
A la exploración destacaba buena hidratación y perfusión. Normotenso. Ausencia de adenovisceromegalias. Cicatriz de incisión pararrectal derecha. Riñón palpable en fosa iliaca derecha (Fig. 1) y pulsos periféricos conservados. Normal volumen urinario. Tacto Rectal: próstata fibroelástica volumen II/IV.

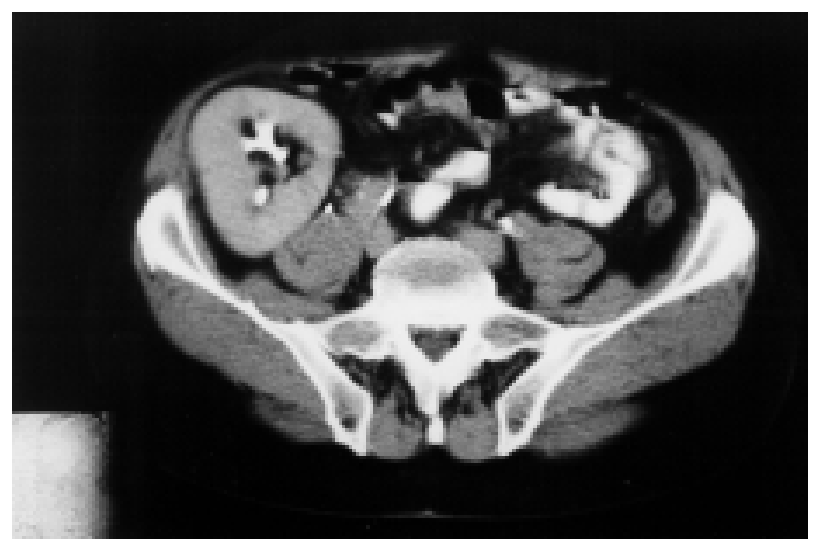

FIGURA 1. Imagen scannográfica: injerto renal funcionante en F.I.D.

Analítica: hemograma, coagulación, enzimas hepáticos y F. Alcalina normales; urea 48 mgr/dl; calcemia 9,6 mgr/dl. Aclaramiento de creatinina $68 \mathrm{ml} /$ minuto y orina de ph neutro sin leucohematuria. PSA 3,20 ngr/ml.

ECG: trazado de hipertrofia ventricular izqda. RFx Tórax: cardiomegalia izqda. Ecografia Renal: riñones pequeños, sin corteza, hiperecogénicos y quísticos, presentando el derecho área redondeada de ecoestructura heterogénea, de $3 \times 3,5 \mathrm{cms}$, localizada en su polo inferior junto a imagénes transónicas de $2 \mathrm{cms}$ compatibles con quistes (Fig. 2).

Se completó estudio urológico (scanner, serie ósea,...) demostrándose una lesión sólida hipercaptante polar inferior en riñón natural derecho (Fig. 3) sin otra afectación locoregional. Con la sospecha de tumor renal se procedió a nefrectomía total por incisión de lumbotomía derecha, con resultado histológico de hipernefroma bien diferenciado (pT2NoMo; GI).

Después de una década de seguimiento, el injerto renal se encuentra funcionante, las cifras de tensión arterial estables, y controles ecográficos anuales del riñón nativo izquierdo normales.

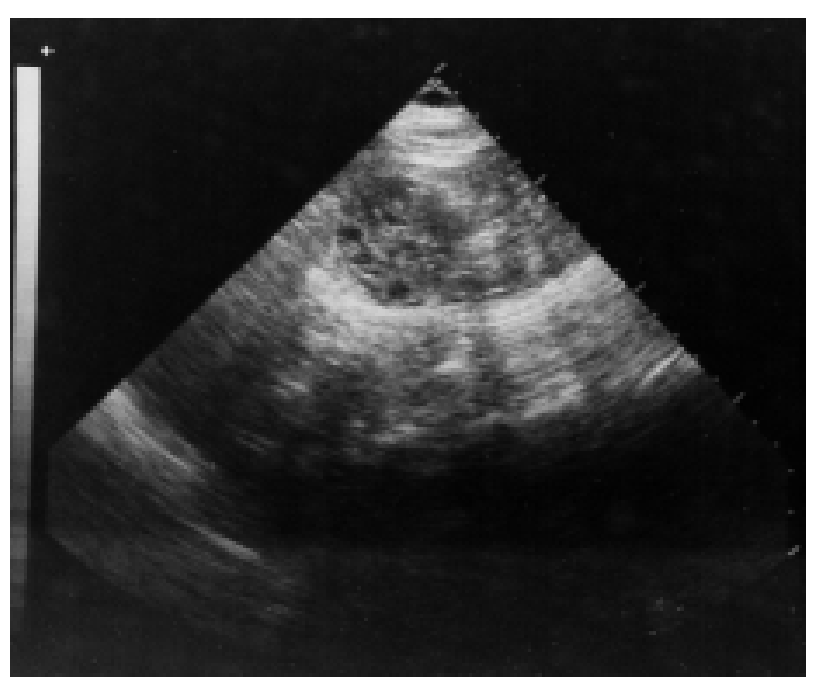

FIGURA 2. Ecografia renal: área heterogénea de 3 x 3,5 cm en polo inferior de riñón izquierdo con imágenes transónicas de $2 \mathrm{~cm}$.

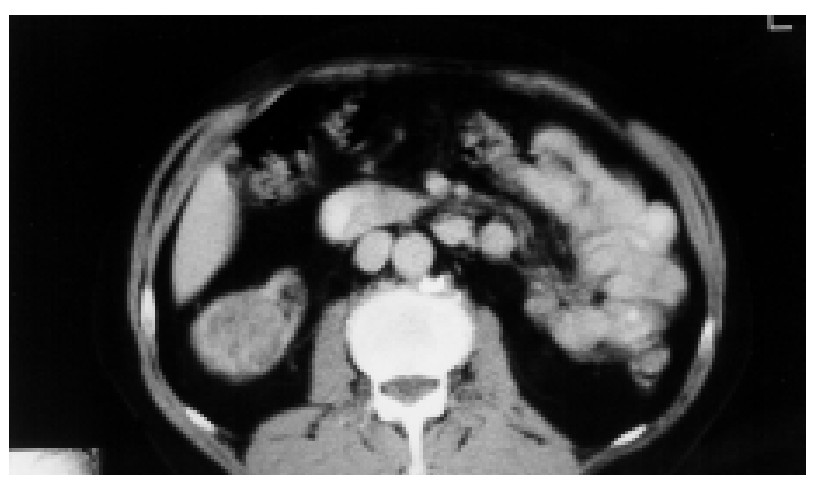

FIGURA 3. TAC abdominal: lesión sólida hipercaptante en tercio inferior de riñón natural derecho.

\section{DISCUSIÓN}

En 1977, Dunnill describió, por primera vez, en enfermos dializados durante largo tiempo, la aparición progresiva de múltiples quistes renales en los que la patología de origen no era quística $^{3}$.

La prevalencia de quistes renales adquiridos oscila entre un 40-50\%, variando según el tiempo de diálisis ${ }^{4,5}$; está descrito que el volumen de los riñones disminuye durante los tres primeros años de filtración dialítica y a partir de entonces comienza la formación quística, incrementándose su incidencia hasta el 90\% tras 5-10 años de hemodiálisis ${ }^{1}$.

Estudios morfológicos, procedentes de informes de autopsia y piezas de nefrectomía, reve- 
lan que los quistes afectan tanto a la médula como a la corteza midiendo desde unos milímetros a varios centímetros, siendo múltiples y bilaterales ${ }^{6}$.

La etiopatogenia de la E.R.Q.A no está aclara$\mathrm{da}^{1}$. La teoría más aceptada que explica la génesis del quiste es que los riñones insuficientes se tornan isquémicos y los glomérulos son reemplazados por tejido fibrótico; de esta manera, desciende el efecto lavado del flujo urinario en los túbulos renales produciéndose la obstrucción tubular y el inicio de la formación quística ${ }^{7}$; otros piensan que se debería a la producción de sustancias quistogénicas, como consecuencia de la uremia mantenida, que la hemodiálisis no puede eliminar ${ }^{5}$.

Los pacientes urémicos con quistes renales adquiridos generalmente permanecen asintomáticos, o complicarse en forma de hemorragia intraquística, infección o presentar tumoraciones renales sólidas como adenomas, oncocitomas y $\operatorname{adenocarcinomas}^{2,8}$. La frecuencia real del carcinoma renal no es bien conocida, pero se cree que es 12-18 veces mayor que en la población general, y se estima entre el 5-19\% ${ }^{1,9}$.

Aunque no está sistematizada la monitorización radiológica habitual de pacientes portadores de E.R.Q.A, hay autores ${ }^{10}$ que sugieren realizar estudios periódicos anuales a partir del tercer año de diálisis por el riesgo a desarrollar una neoplasia maligna.

Los métodos radiográficos por imagen más utilizados en la E.R.Q.A son los ultrasonidos y el scanner. La capacidad para diagnosticar un tumor sólido renal, en este grupo de población, es parecido con ambas técnicas ${ }^{11,12}$; pero cuando las lesiones quísticas son complejas se debe recurrir a la resonancia nuclear magnética o a estudios invasivos ${ }^{13}$.

El potencial maligno de los tumores renales en pacientes con fracaso renal crónico es bajo, ya que se trata de neoformaciones bien diferenciadas, de pequeñas dimensiones y curso asintomático $^{9}$, tal como sucedió en el enfermo comunicado; existe consenso que ante tumoraciones inferiores a $3 \mathrm{cms}$, la terapéutica puede ser conservadora con seguimiento radiográfico estricto y las lesiones de mayor diámetro, subsidiarias de exéresis renal ${ }^{14}$. Puesto que suelen ser neoplasias de lento crecimiento con escasa tendencia a la inva- sión a distancia ${ }^{1}$ y de menor actividad proliferativa que el cáncer renal clásico, no parece estar justificada la nefrectomía bilateral profiláctica ${ }^{15}$.

\section{REFERENCIAS}

1. KAWAMURA R, MILLARD PR, OLIVER D.: Acquired renal cystc disease. Hinyokika Kiyo 2000; 46: 651-656.

2. DENTON MD, MAGEE CC, OVUWORIE C et al.: Prevalence of renal cell carcinoma in patients with ESRD pretransplantation: a pathologic analysis. Kidney Int 2002; 61: 2201-2209.

3. DUNNILL MS, MILLARD PR, OLIVER D.: Acquired cystic disease of the of the kidneys: a hazard of long term intermitent maintenance haemodialysis. $J$ Clin Pathol 1977; 30: 868-877.

4. HEINZ-PEER G, SCHODER M, RAND $\mathrm{T}$ et al.: Prevalence of acquired cystc kydney disease and tumors in native kydney renal of renal transplant recipients: a prospective US study. Radiology 1995; 195: 667-671.

5. CHOIKE PL.: Acquired cystc kidney disease. Eur Radiol 2000; 10: 1716-1721.

6. SEGERER S, MEISTER P.: Acquired cystc kidney disease in chronic dialysis patients: a retroapective study of 125 autopsies. Pathologe 1998; 19: 292-298.

7. JIANG A, MEISTER P.: Occurrence of renal cystc and tumor in patients under long-term haemodialysis. Zhonghua Zhong Liu Zazhi 1995; 17: 1716-1721.

8. SANT GR, UCCI AA.: Acquired renal cystc disease and adenocarcinoma following renal transplantation: a current urologic perspective. Urol Int 1998; 60: 108112 .

9. JOVANOVIC D, KOVACEVIC Z, IVEK L, SAJINOVIC D et al.: Acquired renal cystc disease and renal carcinoma in patients on chronic haemodialysis. Vojnosanit Pregl 1998; 55: 333-337.

10. SHINGLETON WB, BLALOCK J, BIGLER SA.: Renal cell carcinoma in native kidneys of with stage renal disease. J Miss State Med Assoc 1998; 39: 86-89.

11. TERASAWA Y, SUZUKI Y, MORITA M et al.: Ultrasonic diagnosis of renal cell carcinoma in haemodialysis patients. J Urol 1995; 153: 1644-1647.

12. KLIEM V, KOLDITZ M, BEHREND M et al.: Risk of renal cell carcinoma after kidney transplantation. Clin Transplant 1997; 11: 255-258.

13. YIP SK, CHEE E.: Clinics in diagnostic imaging (46). Renal cell carcinoma in acquired cystc kidney disease. Singapore Med J 2000; 41: 89-91.

14. IKEDA R, SUZUKI K, TSUGAWA R.: Renal cell carcinoma and acquired cystc disease of the kidneys in patients on long-term haemodialysis. Hinyokika Kiyo 1995; 41: 709-717.

15. IKEDA R, TANAKA T, MORIYAMA M et al.: Proliferative activity of renal cell carcinoma associated with acquired cystc disease of the kidney: comparison with typical renal cell carcinoma. Hum Pathol 2002; 33: 22302235 .

Dr. J. Herrera Puerto

C/ Bolivar, 24 - 3ํ C

37004 Salamanca

(Trabajo recibido el 18 diciembre de 2002) 